\title{
Knowledge Spillovers, Congestion Effects, and Long-Run Location Patterns
}

\author{
Gian Italo Bischi ${ }^{1}$, Michael Kopel ${ }^{2}$, Fabio Lamantia ${ }^{3,4}$, and Davide Radi ${ }^{5(凶)}$
}

1 DESP-Department of Economics, Society, Politics, University of Urbino Carlo Bo, 42 Via Saffi, 61029 Urbino, PU, Italy

gian.bischi@uniurb.it

2 Institute of Organization and Economics of Institutions,

University of Graz, Graz, Austria

michael.kopel@uni-graz.at

3 Department of Economics, Statistics and Finance, University of Calabria, 3C Via P. Bucci, 87036 Rende, CS, Italy

fabio.lamantia@unical.it

4 Economics - School of Social Sciences, The University of Manchester, Arthur Lewis Building, Manchester, UK

5 School of Economics and Management, LIUC - Università Cattaneo, 22 C.so Matteotti, 21053 Castellanza, VA, Italy

dradi@liuc.it

\begin{abstract}
We introduce an evolutionary two-country model to characterize long run location patterns of the manufacturing activities of competing multinational enterprises. Firms located in country 1 can decide to offshore their manufacturing activities to country 2. The profitability of production in a country depends on several factors: unitary costs of production, the number of firms that are located in each country, within-country spillovers, and cross-border spillovers. Furthermore, profits in country 2 are influenced by congestion costs. Country 1 is assumed to be technologically advanced and has an advantage in terms of internal spillovers. In contrast, country 2 offers lower production unit cost which, however, may be offset by congestion costs. The firms' (re)location choices are based on a simple comparison of current production costs obtained in the two countries and the dynamics of switching is modeled by a simple replicator dynamics. The global analysis of the resulting one-dimensional dynamical system reveals that a large advantage in terms of unitary production costs encourages the firms to off-shore manufacturing activities to country 2. This off-shoring process stops when congestion costs offset this advantage of country 2 , even though congestion costs do not cause all manufacturing activities to be re-shored to country 1 . The re-shoring process can be accelerated by an increase of within-country spillovers in country 1 , while cross-border spillovers tend to favor a geographic dispersion of manufacturing activities and make location patterns that lead to suboptimal long run outcomes less likely.
\end{abstract}

Keywords: Long run location patterns · Off-shoring · Re-shoring • Knowledge spillovers · Congestion costs $\cdot$ Exponential replicator dynamics $\cdot$ Global dynamics

(C) The Author(s) 2018

P. Commendatore et al. (eds.), The Economy as a Complex Spatial System,

Springer Proceedings in Complexity, DOI 10.1007/978-3-319-65627-4_11 


\section{Introduction}

The off-shoring of manufacturing activities to emerging economies has offered an opportunity to reduce manufacturing costs and has therefore been a common practice for many Multinational Enterprises (MNEs). This phenomenon has provoked massive changes in the organization of industrial activity and in the labor market of developed economies. As a consequence, it has attracted political attention. Governments of the OECD economies have focused on developing incentive-schemes designed to reduce job losses by providing incentives for MNEs to re-shore their manufacturing activities. An increase in re-shoring activity has been observed in recent years, with many MNEs increasingly bringing manufacturing activity back home. Empirical evidence documents the increase in re-shoring activity, but also indicates that in comparison to firms' off-shoring activities the process is still limited, see Backer et al. (2016).

The identification of drivers that cause firms to choose particular locations for their activities still attracts increasing attention from scholars. The literature on International Business has identified a variety of drivers that guide the location decision of MNEs and has provided empirical tests. Following the literature (Alcácer et al. (2013)), location drivers can be gathered in two broad categories: endowment drivers and agglomeration drivers. The stream of literature based on endowment drivers tries to explain the location patterns of manufacturing activity in terms of location traits such as physical infrastructure, quality of the labor force, and cultural distance, see, e.g., Coughlin et al. (1991) and Flores and Aguilera (2007). In more recent studies, focus has been put on institutional features such as contractual hazards and appropriation concerns (Henisz (2000)) and on the enforcement of property rights (Lee and Mansfield (1996)). Differently, the stream of literature based on agglomeration drivers takes into account positive externalities that derive from the geographical clustering of manufacturing activities, for example, due to technological spillovers, access to specialized labor, and access to specialized intermediate inputs, see Marshall (1982). Then, according to this approach, the presence of knowledge spillovers is country-specific, but also depends on the location choice of firms. In other words, it has an endogenous component that depends on firms observing the economic environment and choosing the location strategically. More recent literature puts increased attention to strategic interaction between MNEs in oligopolistic markets and the impact on agglomeration phenomena; see, e.g., Alcácer and Chung (2007). These agglomeration economies have been further studied with formal models, e.g., in David and Rosenbloom (1990), Krugman (1991), Bischi et al. (2003a) and Bischi et al. (2003b), and have been empirically documented in global and international settings, see, e.g., Carlton (1983) and Mariotti et al. (2010).

In the current work, we develop a dynamic model that considers a combination of endowment drivers and agglomeration drivers. The model describes the repeated manufacturing location decisions of firms that choose between offshoring and re-shoring their activities to benefit from a reduction in manufacturing costs taking into account knowledge spillovers between firms. Firms are based 
in a developed country, called country 1 , and have the option to off-shore manufacturing activity to an emerging country, called country 2 . The unit costs of production in country 1 are higher but are decreased by cost-reducing externalities, to which we refer as within-country spillovers. These within-country spillovers depend on the share of manufacturing activity in country 1. More specifically, the higher the level of manufacturing activity, the higher are the spillovers and the cost-reducing externalities. In this case, the level of spillovers co-evolves over time with the share of manufacturing activity and crucially influences the strategic location choices of firms. Manufacturing costs can also be reduced by cross-border spillovers that capture the benefit of knowledge developed in country $i$ that spills over to the other country $j$ and reduces the costs of production there. In line with empirical evidence which reveals that knowledge spillovers are geographically localized and that knowledge transfer decreases with distance even within the same firm (see, e.g., Adams and Jaffe (1996, Rosenthal and Strange 2003 and Jaffe et al. 1993)), we assume that cross-border spillovers per unit of production are smaller than (or equal to) within-country spillovers. In our framework, knowledge spillovers can also be developed within country 2 , but the related cost-reducing externalities might differ from country 1 . This assumption is motivated by empirical evidence which highlights that technological spillovers and innovation activity vary across locations due to differences in initial endowments, the actions of actors engaged in $\mathrm{R} \& \mathrm{D}$ (governments, universities and firms), the links among those actors, and the differences in educational systems and regulation, see, e.g., Nelson (1993) and Furman et al. (2002). The effect of endowment drivers are simply captured by an additional linear cost component - representing congestion costs - that depends on the level of activity in country 2. Congestion costs measure the level, the quality, and the (in)efficiencies of the infrastructure and facilities that a country can offer. It is an essential feature of a manufacturing site that has a crucial impact on the location choice of MNEs. Moreover, this feature is country-specific as it cannot be easily transferred from country to country and it cannot be modified in the short run. It depends on the level of education, the structural investments undertaken in the past, the resources invested in research in the last decades and the quality of the institutions. For the sake of simplicity, and without loss of generality, the congestion costs are assumed to be zero for country 1 .

The cost-reducing effect due to internal (within-country) and external (crossborder) spillovers are modeled as in Bischi et al. (2003a) and Bischi et al. (2003b) and we adopt their functional form for the unit costs of manufacturing. The novel element in our model is that we introduce congestion costs. The firms' location decisions are based on the relative performance of producing at home in country 1 and producing in the foreign country 2 . The switching between decisions is described by a replicator dynamics, see, e.g., Hofbauer and Sigmund (2003). The evolutionary framework proposed in this chapter links firm's location choices with internal and external knowledge spillovers and congestion costs. We illustrate how such a highly stylized dynamical model can be used to derive policy implications. We further shed light on aspects such as the combined impact of 
knowledge spillovers and congestion costs on the long run location patterns of manufacturing activity. In particular, we try to improve our understanding of which combinations of within-country spillovers and congestion costs lead to reshoring of manufacturing activity, the effects of cross-border spillovers on the relocation choice, the existence of suboptimal location patterns and the parameter settings that lead to optimal (minimum production costs) outcomes. We also try to identify parameters that have the biggest impact on location patterns and, hence, might be suitable for economic policy.

As the literature reports that over time off-shoring of manufacturing has lead to a substantial increase in production costs in the foreign countries, we focus our analysis on the effect of congestion costs on the global dynamics of location patters that result from our evolutionary model. The investigation starts with the global analysis in absence of cross-border spillovers and considers three different configurations of unit costs of production. For each configuration, three cases of different within-country spillovers are considered. Hence, our analysis considers nine different scenarios ranging from the benchmark case in which the two countries differ only in congestion costs to an extreme situation in which country 2 offers a rather large cost advantage while country 1 offers large costreducing within-country spillovers. Then, the analysis is completed considering cross-border spillovers and asymmetric cases in which the firms benefit from cross-border spillovers only operating in one of the two countries.

The investigation reveals that the particular combination of within-country and cross-border spillovers crucially shape the spatial distribution of the industrial activities between the two countries. In particular, if there is no difference in unit production cost, the manufacturing activity tends to be polarized in one of the two countries. In this case, congestion costs reduce off-shoring of manufacturing activity to country 2 . In contrast, the possibility to benefit from a large advantage in unit production costs if manufacturing is located in country 2 accelerates off-shoring activities and, for sufficiently high congestion costs, leads to a location pattern in which the manufacturing activity is spread between the two countries. It is worth observing that large congestion costs increase re-shoring activities, but do not completely eliminate manufacturing activity in country 2 . In fact, depending on the strategic location choices of firms, congestion costs are negligible if the level of manufacturing activity in country 2 is low. In this context, the presence of cross-border spillovers reduces the polarization of the manufacturing activity in a single country. The optimality of the geographic allocation of the manufacturing activity in terms of resulting costs of manufacturing is another important aspect. Our investigation reveals that congestion costs and asymmetric within-country spillovers can lead to equilibrium location patterns that are suboptimal. This occurs if firms concentrate their manufacturing activities in a location that does not ensure the lowest production costs. The presence of cross-border spillovers reduces the likelihood of long run location patterns that lead to such suboptimal situations, while a counter-intuitive effect is observed in presence of asymmetric cross-border spillovers. In particular, when firms can absorb the knowledge spillovers coming from country 2 only, 
a reduction of within-country spillovers in country 2 contributes to an increase in off-shoring. This finding highlights that the conventional wisdom put forward by the International Business literature that firms will be attracted to locations with larger knowledge activity, see, e.g., Alcácer and Chung (2007), does not hold in general and, specifically, does not hold in case of asymmetric outflows of spillovers.

The structure of the chapter is as follows. Section 2 introduces the twocountry model. Section 3 identifies the equilibria of the model, their local stability and their optimality. Section 4 investigates the global dynamics of the location patterns for different configurations of the parameters and studies the effect of the congestion costs. Section 5 concludes. All proofs are given in the Appendix.

\section{The Model}

Let us consider a population of firms that manufacture a homogenous product. There are two countries indexed by $i=1,2$. Total production is sold at a positive price in a global market characterized by a given demand function. Total production quantity is normalized to one and we are interested in the share of total production that is manufactured in country $i$. The firms choose whether to produce in country 1 or to locate production in country 2 . At each discrete time $t \in \mathbb{N}$, the firms' choices determine the fraction $x(t)$ of production in country 1 and the complementary fraction $1-x(t)$ in country 2 . The current allocation determines production costs in each country. In particular, we assume that producing in country 1 and country 2 implies the following costs,

$$
\begin{aligned}
& C_{1}(x(t))=\frac{c_{1}}{1+\beta_{1} x(t)+\gamma_{12}(1-x(t))} \quad \text { and } \\
& C_{2}(x(t))=\frac{c_{2}}{1+\beta_{2}(1-x(t))+\gamma_{21} x(t)}+k(1-x(t)) .
\end{aligned}
$$

The unit production costs in country $i=1,2$ are denoted by $c_{i}$ and $\beta_{i}$ is the coefficient of within-country spillovers in country $i$. We assume that country 1 is more efficient. In particular, we consider country 1 to be a technology leader (a developed economy) and country 2 to be a technology laggard (a developing economy). Since production costs in a technologically advanced country are typically higher (e.g. due to higher wages) than the costs of production in country 2 that is a technology laggard, we consider $c_{1} \geq c_{2} \geq 0$. The cost-reducing externalities related to internal spillovers are higher in country 1 than in country $2, \beta_{1} \geq \beta_{2}$. Cross-border spillovers are represented by $\gamma_{j i}$ which capture costreducing externalities in country $j$ related to knowledge spillovers coming from country $i \neq j$, see similarly Bischi and Lamantia (2002), Bischi et al. (2003a) and Bischi et al. (2003b). Knowledge spillovers are geographically constrained, see, e.g., Rosenthal and Strange (2003) and Jaffe et al. (1993), and the benefits of knowledge transfer decreases with distance even within the same firm, see Adams and Jaffe (1996) and Alcácer and Chung (2007). It follows that the benefits from cost-reducing spillovers are assumed to be higher in the country in 
which (manufacturing) know-how is developed. In other words, $\beta_{i} \geq \gamma_{j i}$. Finally, $k$ is a coefficient that measures the effect of congestion, a cost-increasing externality related to overcrowding which increasingly becomes important if the level of manufacturing activity in country 2 increases. A firm operating in country 1 does not suffer from congestion costs due to, e.g., better infrastructure. These arguments yield the following parameter constraints.

Assumption 1. We assume that $c_{1} \geq c_{2}>0, \beta_{1} \geq \beta_{2} \geq 0, \beta_{2} \geq \gamma_{12} \geq 0$, $\beta_{1} \geq \gamma_{21} \geq 0, k \geq 0$.

Note that cost function $C_{1}$ is monotonically decreasing with respect to $x$, the fraction of manufacturing activity located in country 1 , while the cost function $C_{2}$ is U-shaped. We assume that the evolution of the share of manufacturing activity located in country 1 , i.e. $x(t) \in[0,1]$, is given by the following exponential replicator equation (see Cabrales and Sobel (1992)):

$$
x_{i}(t+1)=T(x(t))=(1-\alpha) x(t)+\alpha x(t) \frac{1}{x(t)+(1-x(t)) e^{\beta\left(C_{1}(x(t))-C_{2}(x(t))\right)}} .
$$

This model proposes that the share of manufacturing activity in country 1 increases (decreases) from period $t$ to period $t+1$ if country 1 's production costs in period $t$ are lower (higher) than country 2's production costs. The parameter $\beta>0$ measures the intensity of switching between the locate-production-athome strategy and the off-shore-production strategy. It determines the fraction of firms that move production from one country to the other in their search for lower costs of production. The firms are affected by inertia which is related to difficulties in changing the location choice. This inertia is captured by parameter $\alpha \in[0,1]$. The replicator Equation (2) captures an evolutionary selection mechanism by which better strategies spread in a population of firms. Differently from the classical replicator dynamics, see, e.g., Hofbauer and Sigmund (2003) and references therein, it has the convenient property that the state space $[0,1]$ is invariant under the dynamics of (2). Thus, long run location patterns of the firms are obtained as the steady states of this evolutionary model.

The goal of our work is to analyze the possible long run location patterns of the manufacturing activity and to identify the possible measures that a policymaker can take to influence these location patterns. In this regard, we are interested to understand the role that is played by spillovers and congestion costs if firms choose to produce in country 2 to take advantage of lower production costs and under which circumstances country 1 becomes attractive.

\section{Equilibrium Location Patterns: Local Stability and Efficiency}

The off-shoring of the entire manufacturing activity to country 2 represents an equilibrium of the model (2) as well as concentrating manufacturing in country 1. These are only two of several possible long-run location patterns and the 
possibility to converge to one of these equilibria depends on the initial share of firms that manufacture in country 1 and on the particular parameter values. In the next section, we analyze this aspect by so-called bifurcation diagrams which show the changes of such equilibria and their basins of attraction as congestion costs vary. Our analysis is performed for various configurations of the parameters of the cost functions. The numerical analysis is supported by and combined with analytical results which shed some light on the possible long-run location patterns. In particular, it is possible to prove the following stability properties for the long-run location patterns.

Theorem 1. The model (2), given assumption 1 holds, has the two border equilibria, i.e. $x=1$ and $x=0$, and at most two more equilibria in $(0,1)$. Let us define

$$
k_{T_{1}}=\frac{c_{1}}{1+\gamma_{12}}-\frac{c_{2}}{1+\beta_{2}} \quad \text { and } \quad k_{T_{2}}=\frac{c_{1}}{1+\beta_{1}}\left(\frac{\beta_{1}-\gamma_{12}}{1+\beta_{1}}-\frac{\gamma_{21}-\beta_{2}}{1+\gamma_{21}}\right)
$$

Then,

- if $C_{1}(1)<C_{2}(1)$, i.e. $\frac{c_{1}}{c_{2}}<\frac{1+\beta_{1}}{1+\gamma_{21}}$, equilibria $x=1$ and $x=0$ are both locally asymptotically stable and a repellor exists in $(0,1)$ for $k<k_{T_{1}}$; at $k=k_{T_{1}}$ equilibrium $x=0$ loses stability through either a transcritical or a pitchfork bifurcation and, for $k>k_{T_{1}}$, equilibrium $x=1$ is stable while $x=0$ is unstable.

- if $C_{1}(1)>C_{2}(1)$, i.e. $\frac{c_{1}}{c_{2}}>\frac{1+\beta_{1}}{1+\gamma_{21}}, x=1$ is unstable and $x=0$ is locally asymptotically stable for $k<k_{T_{1}}, x=0$ loses stability at $k=k_{T_{1}}$ and for $k>k_{T_{1}}$ equilibria $x=1$ and $x=0$ are both unstable and at least one internal fixed point exists.

- if $C_{1}(1)=C_{2}(1)$, i.e. $\frac{c_{1}}{c_{2}}=\frac{1+\beta_{1}}{1+\gamma_{21}}, x=0$ is local asymptotically stable with basin of attraction given by $\mathscr{B}(0)=[0,1)$ and $x=1$ is unstable, at $k=k_{T_{2}}$ equilibrium $x=1$ becomes stable through a transcritical bifurcation, for $k_{T_{2}}<$ $k<k_{T_{1}}$ both $x=1$ and $x=0$ are asymptotically stable, at $k=k_{T_{1}} a$ transcritical bifurcation occurs and for $k>k_{T_{1}}$ equilibrium $x=0$ is unstable and equilibrium $x=1$ is locally asymptotically stable with $\mathscr{B}(1)=[0,1)$.

The Theorem reveals that it is feasible to produce in the technologically advanced country 1 if the higher unit costs of production are offset by higher technological spillovers, while the congestion costs do not affect the stability of this long-run location pattern. After all, these costs are related to the concentration of manufacturing activity in the less technologically advanced country and the cost effect is marginal when production activity is mostly located in country 1 . On the contrary, large congestion costs make off-shoring of manufacturing activity infeasible.

Although some insights on the long-run location patterns can be gained from analytical derivations, the complicated form of the cost functions makes it difficult to identify all equilibria of the model and the type of bifurcations that are responsible for their existence or stability. Nevertheless, it is possible to consider 
some benchmark cases that allow us to develop insights on the changes in the more complicated scenarios. We start by abstracting from congestion costs. In this case, it is possible to prove the following result.

Theorem 2 (No congestion costs). Let $k=0$. Then,

- when $C_{1}(0)>C_{2}(0)$, i.e. i.e. $\frac{c_{1}}{c_{2}}>\frac{1+\gamma_{12}}{1+\beta_{2}}$, and either $\beta_{1}>\gamma_{12}$ or $\beta_{2} \neq \gamma_{21}$, the long-run location pattern $x=0$ is always at least locally stable. Specifically, for $C_{1}(1)>C_{2}(1)$, we have $\mathscr{B}(0)=[0,1)$, for $C_{1}(1)=C_{2}(1)$ a transcritical bifurcation occurs through which the equilibrium $x^{*}$, given by

$$
x^{*}=\frac{c_{1}\left(1+\beta_{2}\right)-c_{2}\left(1+\gamma_{12}\right)}{c_{1}\left(\beta_{2}-\gamma_{21}\right)+c_{2}\left(\beta_{1}-\gamma_{12}\right)}
$$

merges with the equilibrium $x=1$ and becomes feasible, i.e. $x^{*} \in[0,1]$. For $C_{1}(1)<C_{2}(1)$, the equilibria $x=1$ and $x=0$ are both locally asymptotically stable with basin of attraction given by $\mathscr{B}(1)=\left(x^{*}, 1\right]$ and $\mathscr{B}(0)=\left[0, x^{*}\right)$, respectively. The fixed point $x^{*}$ is a repellor. For the special case $c_{1}=c_{2}$, $\beta_{1}=\beta_{2}$ and $\gamma_{12}=\gamma_{21}=0, x^{*}=\frac{1}{2}$, we have that equilibria $x=0$ and $x=1$ are both asymptotically stable with $\mathscr{B}(0)=\left[0, \frac{1}{2}\right)$ and $\mathscr{B}(1)=\left(\frac{1}{2}, 1\right]$.

- when $C_{1}(0)=C_{2}(0)$ (which implies $\beta_{2}=\gamma_{12}$ and $c_{1}=c_{2}$ under assumption 1) and either $\beta_{1}>\gamma_{12}$ or $\beta_{2} \neq \gamma_{21}$, it follows that $\mathscr{B}(1)=(0,1]$ for $C_{1}(1)<$ $C_{2}(1)$, the fixed points of model (2) fill the region $[0,1]$ when $C_{1}(1)=C_{2}(1)$ and $\mathscr{B}(0)=[0,1)$ when $C_{1}(1)>C_{2}(1)$.

- in case of total absorption of cross-border spillovers, i.e. $\beta_{1}=\gamma_{12}$ and $\beta_{2}=\gamma_{21}$, when the production costs are symmetric, i.e. $c_{1}=c_{2}$, the fixed points of model (2) fill the region [0,1], otherwise the long-run outsourcing location pattern 0 is the only locally stable equilibrium such that $\mathscr{B}(0)=[0,1)$.

The Theorem underlines that in the absence of congestion costs, off-shoring of manufacturing represents a stable long-run location pattern which may or may not coexist with the equilibrium where manufacturing occurs only in the home country 1. Moreover, if knowledge is transferable between countries without losses (i.e. internal and cross-border spillovers are identical), then it is attractive to off-shore manufacturing to country 2 . In this case, the absence of congestion cost and the presence of even a small production cost advantage offered by country 2 , makes off-shoring of manufacturing the unique long-run location pattern. The scenario changes when production in country 2 implies congestion costs. Assuming that cost-reducing know-how is perfectly transferable between countries, it is possible to prove the following results.

Theorem 3. Let $\beta_{1}=\gamma_{21}, \beta_{2}=\gamma_{12}$ and $k>0$. If $c_{1}=c_{2}$, then equilibrium $x=1$ is asymptotically stable with basin of attraction given by $\mathscr{B}(1)=(0,1]$, otherwise equilibrium $x=1$ is never asymptotically stable and,

- when $\beta_{1}>1+2 \beta_{2}$ and $\beta_{1} \neq \beta_{2}$, for $k<k_{F}$, where

$$
k_{F}=\frac{4\left(\beta_{1}-\beta_{2}\right)\left(c_{1}-c_{2}\right)}{\left(\beta_{1}+1\right)^{2}+2 \beta_{1} \beta_{2}}
$$


the equilibrium $x=0$ is locally stable with basin of attraction given by $\mathscr{B}(0)=[0,1)$. At $k=k_{F}$, two fixed points appear through a fold bifurcation:

$$
x_{1,2}^{*}=\frac{\left(1-\beta_{1}+2 \beta_{2}\right) k \pm \sqrt{k\left[\left(\beta_{1}+1\right)^{2} k+2 \beta_{1} \beta_{2} k+4\left(\beta_{2}-\beta_{1}\right)\left(c_{1}-c_{2}\right)\right]}}{2 k\left(\beta_{2}-\beta_{1}\right)}
$$

for $k_{F}<k<k_{T_{1}}$, where

$$
k_{T_{1}}=\frac{c_{1}-c_{2}}{1+\beta_{2}},
$$

the fixed point $x=0$ is asymptotically stable with basin of attraction given by $\mathscr{B}(0)=\left[0, x_{2}^{*}\right)$, while the fixed point $x_{1}^{*}$ is either stable with basin of attraction $\mathscr{B}\left(x_{1}^{*}\right)=\left(x_{2}^{*}, 1\right)$ or it loses stability through a period doubling bifurcation. Moreover, at $k=k_{T_{1}}$ the equilibrium $x_{2}^{*}$ merges with equilibrium $x=0$ which looses its stability through a transcritical bifurcation. For $k>k_{T_{1}}$, both equilibria $x=0$ and $x=1$ are unstable and the internal fixed point is either stable with basin of attraction $\mathscr{B}\left(x_{1}^{*}\right)=(0,1)$, or it loses stability through a flip bifurcation.

- when $\beta_{1}<1+2 \beta_{2}$ and $\beta_{1} \neq \beta_{2}$, for $k<k_{T_{1}}$ the fixed point $x=0$ is asymptotically stable with basin of attraction given by $\mathscr{B}(0)=[0,1)$, while at $k=k_{T_{1}}$ the fixed point $x=0$ loses stability through a transcritical bifurcation and the internal fixed point, i.e.

$$
x^{*}=\frac{\left(1-\beta_{1}+2 \beta_{2}\right) k+\sqrt{\left(1-\beta_{1}+2 \beta_{2}\right)^{2} k^{2}+4 k\left(\beta_{1}-\beta_{2}\right)\left(c_{2}-c_{1}+\left(1+\beta_{2}\right) k\right)}}{2 k\left(\beta_{2}-\beta_{1}\right)}
$$

appears which, for $k>k_{T_{1}}$, is either locally asymptotically stable, with basin of attraction $\mathscr{B}\left(x^{*}\right)=(0,1)$, or it looses stability through a flip bifurcation.

- when $\beta_{1}=\beta_{2}$, for $k<\frac{c_{1}-c_{2}}{1+\beta_{1}}$ the fixed point 0 is locally asymptotically stable with basin of attraction given by $\mathscr{B}(0)=[0,1)$, while at $k=\frac{c_{1}-c_{2}}{1+\beta_{1}}$ the equilibrium looses stability through a transcritical bifurcation and the internal fixed point

$$
x^{*}=1-\frac{c_{1}-c_{2}}{k\left(1+\beta_{1}\right)}
$$

appears and for $k>\frac{c_{1}-c_{2}}{1+\beta_{1}}$ it is locally asymptotically stable with basin of attraction $\mathscr{B}\left(x^{*}\right)=(0,1)$.

This analytical result underlines that if cross-border spillovers equal withincountry spillovers, the firm will choose not to locate the entire manufacturing activity in the country that has a production cost disadvantage. Intuitively, the possibility to benefit from spillovers independently of where know-how is generated eliminates the unique strength of the technologically advanced country, i.e. the additional cost reduction due to higher within-country spillovers. Thus, country 2 benefits from outgoing spillovers and manufacturing in this country 
becomes the unique long-run location pattern. However, Theorem 3 also points out that high congestion costs tend to offset the production cost advantage of country 2 and makes a mixed-location strategy the unique long-run location pattern. A deeper investigation for more general scenarios requires a numerical analysis which is developed in the next section. Before doing that, it is worth addressing the optimality of the long run location patterns. Indeed, our evolutionary model allows for long-run location patters which are suboptimal (in terms of manufacturing costs) as specified in the following Theorem.

Theorem 4. Off-shoring the entire production volume to country 2 ensures lower equilibrium production cost whenever $k<\hat{k}$, while locating production in country 1 does so whenever $k>\hat{k}$, where

$$
\hat{k}=\frac{c_{1}-c_{2}+c_{1} \beta_{2}-c_{2} \beta_{1}}{\left(1+\beta_{1}\right)\left(1+\beta_{2}\right)}
$$

Theorem 4 underlines that spreading the production over the two countries is always a suboptimal choice in terms of production costs. Moreover, it implies the following result.

Corollary 1. Off-shoring the entire production volume to country 2 is a suboptimal equilibrium choice whenever $k>\hat{k}$, while locating production in country 1 is so whenever $k<\hat{k}$.

\section{Location Patterns: The Role of Knowledge Spillovers and Congestion Costs}

The aim of this section is to study the effects that congestion costs and internal and external knowledge spillovers have on the long run location patters. In order to do so, we investigate the global dynamics of model (2) by numerical analysis. In particular, we employ bifurcation diagrams that show the dependence of long run location patterns, i.e. the long run share of firms $x$ that locate production in country 1 , if congestion costs, $k$, vary from a situation of no congestion costs, $k=0$, to $k=2$. Bifurcation diagrams are helpful as they illustrate the equilibrium location patterns and their basins of attraction for each value of the congestion costs. The investigation is conducted by normalizing unit costs in country, i.e. $c_{1}=$ 1 , and considering three values of unit costs in country $2, c_{2}$. The first case is $c_{1}=$ $c_{2}$, i.e. no cost advantage from producing in country 2 . The second case is $c_{1}=\frac{3}{2} c_{2}$, i.e. there is a small cost advantage if firms produce in country 2. The third case is $c_{1}=10 c_{2}$, i.e. there is a large cost advantage if firms produce in country 2 . For each of these three cases, three different levels of internal spillovers are considered: symmetric within-country spillovers, i.e. $\beta_{1}=\beta_{2}$; a small advantage of country 1 regarding internal spillovers, specifically $\beta_{1}=\frac{3}{2} \beta_{2}$; and a large advantage of country 1 regarding internal spillovers, i.e. $\beta_{1}=2 \beta_{2}$.

Our first numerical results we report describe the location patterns without cross-border spillovers $\left(\gamma_{12}=\gamma_{21}=0\right)$, see Figs. 1 and 2. The bifurcation diagrams in Fig. 1 reveal that the congestion costs in country 2 have a significant 
impact on the location decisions of firms. In particular, when the costs of production in the two countries are identical, i.e. $c_{1}=c_{2}$, and internal spillovers are identical as well, i.e. $\beta_{1}=\beta_{2}$, the congestion costs reduce the chances that firms locate production in country 2 . The yellow region in this figure represents the basin of attraction of the fixed point $x=0$ (i.e. all production occurs in country 2), that first shrinks and eventually disappears when congestion costs keep increasing. This highlights that the set of initial allocation of manufacturing activity which eventually lead to location patterns where the entire manufacturing occurs in country 2 shrinks and then disappears. On the contrary, the dark-green region represents the basin of attraction of the fixed point $x=1$ (i.e. all production occurs in country 1). This region grows and the fixed point 1 eventually becomes the only asymptotically stable attractor with basin of attraction given by $\mathscr{B}(1)=(0,1]$ when congestion costs increase. This effect is further pronounced when firms that locate production in country 1 also benefit from higher within-country spillovers, i.e. $\beta_{1}>\beta_{2}$. This can be seen in the first row of Fig. 1 which shows the change in the basins of $x=0$ (yellow region) and in the basin of $x=1$ (dark-green region) for increasing internal spillovers. The numerical findings confirm the analytical results in Theorem 1 and, in addition, illustrate that manufacturing activity tends to be polarized in one of the two countries. It is worth pointing out that the coexistence of the yellow and dark-green regions indicates that for a range of congestions costs $k$ the long run location pattern is path dependent, i.e. the long-run outcome of the evolutionary switching process depends on the initial share $x_{0}$ of firms that manufacture in country 1 . The model also admits an internal mixed equilibrium $x^{*} \in(0,1)$ which represents a pattern where parts of the manufacturing activity occurs in country 1 while the remaining share of firms manufacture in country 2. Such an equilibrium is a repellor and lies on the border of the basins of attraction of the two asymptotically stable fixed points $x=0$ and $x=1$. More formally, $\mathscr{B}(1)=\left[0, x^{*}\right)$ and $\mathscr{B}(1)=\left(x^{*}, 1\right]$. Increasing congestion costs causes the interior fixed point to merge with the fixed point $x=0$ and then to disappear through a transcritical bifurcation. Due to this bifurcation, the fixed point $x=0$ becomes unstable. Hence, production will not be located in country 2 any longer for sufficiently large congestion costs.

Identical unit costs, $c_{1}=c_{2}$, do not lead to a long run location pattern with a positive share of manufacturing occurring in both countries. The only possible long-run location patterns are that either all manufacturing is done in country 1 or all production is carried out in country 2. A similar result is obtained if $c_{2}$ is only slightly lower than $c_{1}$; see the bifurcation diagrams in the second row of Fig. 1. Even in this case, as congestion costs increase, production in country 2 becomes less appealing and it shrinks the set of initial conditions which lead to manufacturing activity solely occurring in country 2 in the long run. For sufficiently high congestion costs, all production activity is located in country 1.

The situation is different when country 2 offers a large cost advantage. This situation is arguably akin to the situation MNEs faced when they started offshoring their activities in the 1990s. The last row of Fig. 1 shows a scenario where 

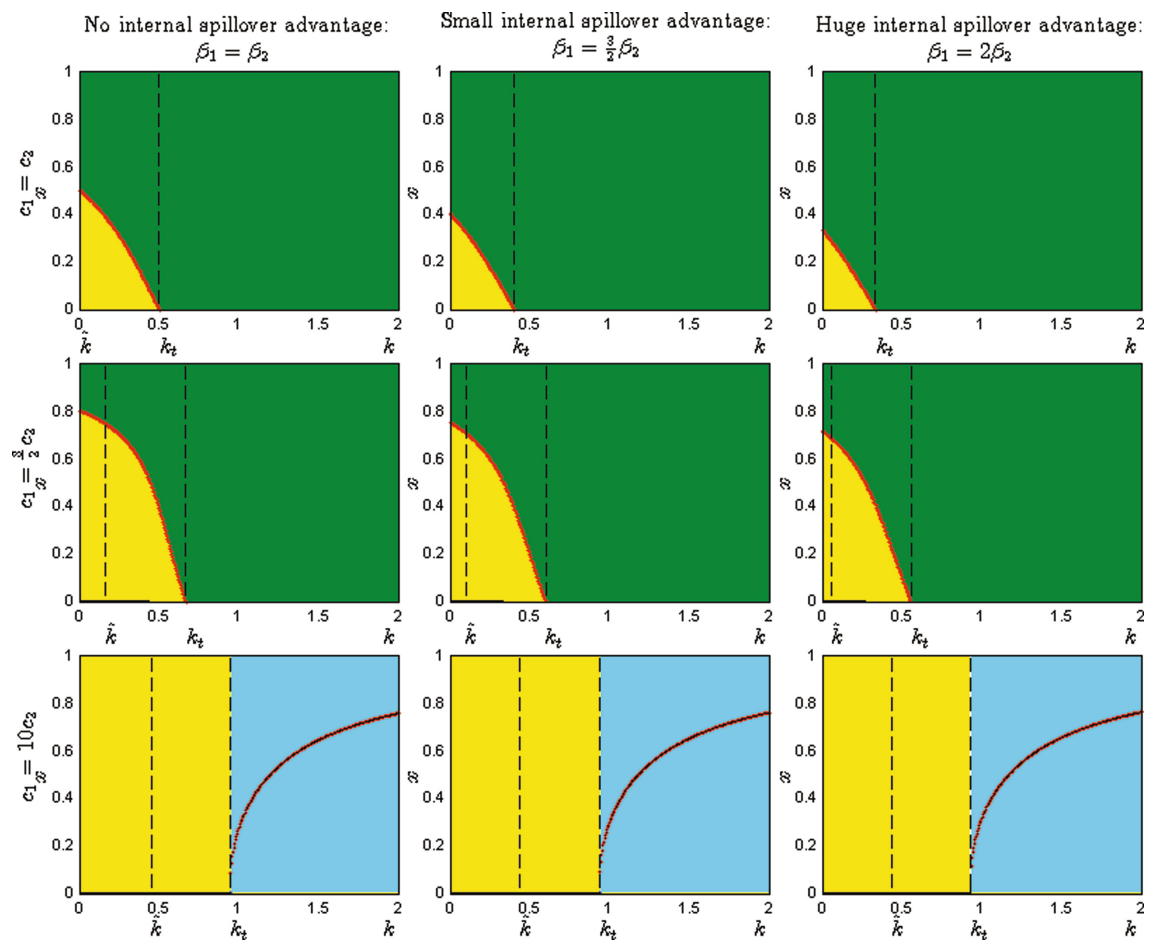

Fig. 1. One-dimensional bifurcation diagrams where congestion costs in country 2, i.e. $k$, is the bifurcation parameter and varies between 0 and 2 . The bifurcation diagrams are reported in three different rows. In the first row, the $\frac{c_{1}}{c_{2}}$ ratio is equal to 1 , which means that there is no cost advantage in country 2. In the second row, the ration is $\frac{3}{2}$, which means a relative cost advantage of country 2 . In the last row, unit cost of production (excluding congestion costs and spillovers) in country 1 is ten times the unit cost in country 2. For each row there are three bifurcation diagrams. The first column represents the situation of no internal spillover advantage, $\beta_{1}=\beta_{2}$. The second column represents the situation of small internal spillover advantage, $\frac{\beta_{1}}{\beta_{2}}=\frac{3}{2}$. The last column represents the situation of a large internal spillover advantage, $\frac{\beta_{1}}{\beta_{2}}=2$. The bifurcation diagram includes the basins of attraction as well. In particular, the basin of attraction of equilibrium $x=0$ is depicted in yellow, the basin of equilibrium $x=1$ is depicted in dark green, and the basin of the stable internal fixed point is in cyan. The values of the remaining parameters are as follows: $c_{1}=1, \beta=1, \beta_{1}=1, \alpha=1, \gamma_{12}=\gamma_{21}=0$.

the cost of production (excluding congestion costs and spillovers) in country 1 is ten times the cost of production in country 2 . Here, a slight change in congestion costs might trigger a completely different location pattern. More specifically, if the congestion costs increase and cross the bifurcation value $k_{T_{1}} \approx 1$, the long run location patterns changes from a situation in which the firm chooses to produce solely in country 2 to a scenario in which production only partially occurs in country 2. Formally, for $k=k_{T_{1}}$, see (5), an internal fixed point appears through 
a transcritical bifurcation. This equilibrium is an attractor and is marked in red. In this scenario, if congestion costs are sufficiently large, the firms' total manufacturing activity is spread geographically between the two countries. In this case, the internal equilibrium is the only asymptotically stable fixed point and its basin of attraction is represented by the cyan region. Increasing the intensity of choice, which measures the firms' intensity of switching between the two location strategies, has the only effect of destabilizing the internal equilibrium for increasing congestion costs. In particular, the internal equilibrium undergoes a sequence of period-doubling bifurcations which lead to a chaotic long-run location pattern. See the last row of Fig. 2.
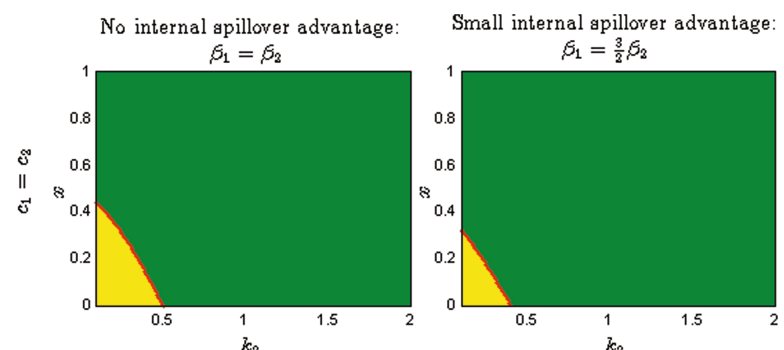

Huge internal spillover advantage:
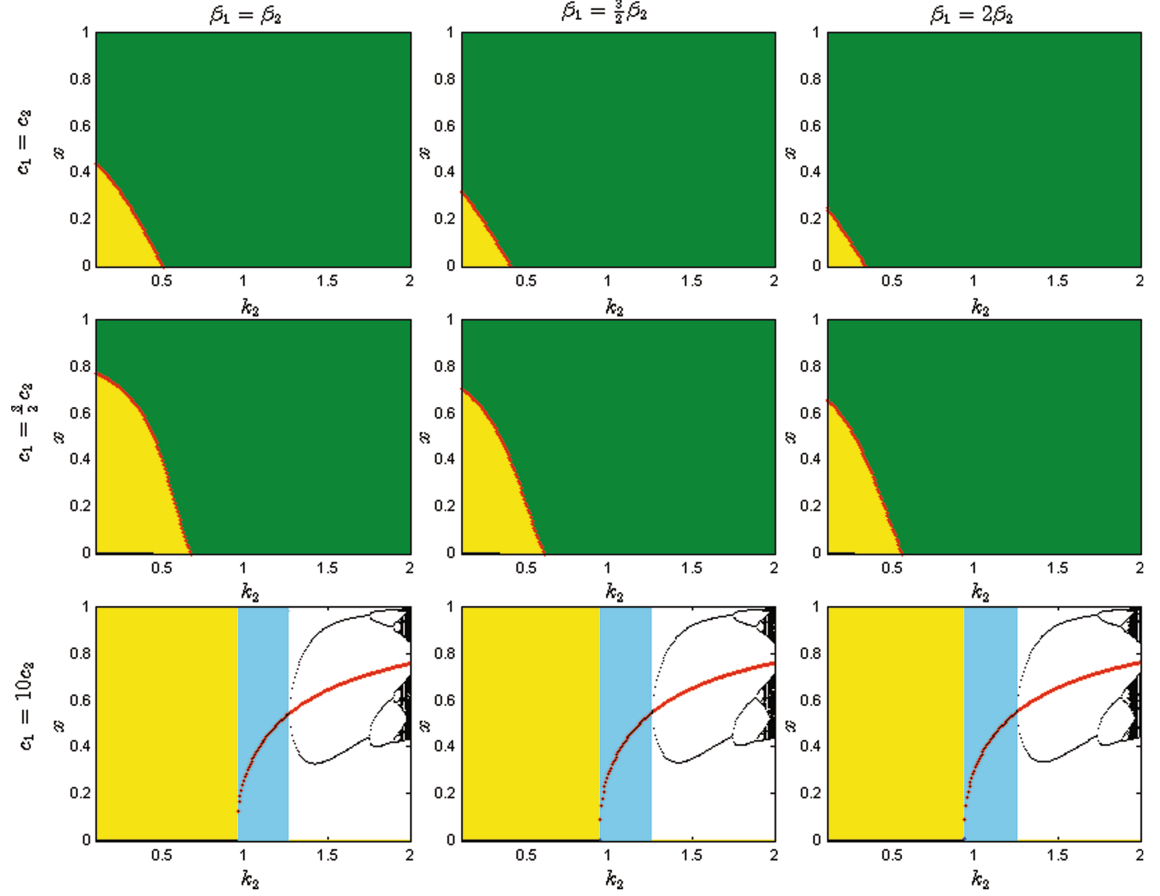

Fig. 2. Same parameter setting as in Fig. 1, except $\beta=10$ (higher intensity of switching).

The evolutionary process of switching between locations in the search for cost reductions can lead to suboptimal equilibrium allocations of production activities in the long run. This is the case represented by the left-top bifurcation diagram in Fig. 1. Here, being $\hat{k}=0$, locating the entire production in country 2 is a suboptimal equilibrium whenever congestion costs are positive, as we have specified in Corollary 1. In fact, due to congestion, firms have to bear higher costs in country 2 than in country 1 . Despite the fact that the fixed 
point $x=0$ is a suboptimal equilibrium, it is asymptotically stable and its basin of attraction (the yellow region) represents a so-called trapping region. The existence of suboptimal and stable equilibria is typical of evolutionary games where agents choose the strategy based on best-relative performance as this might lead to lower absolute profits in the long run; see, e.g., Schaffer (1989).

Summarizing, the analysis reveals that in the absence of cross-border (external) spillovers and if the two countries are characterized by similar costs of production, i.e. $c_{1}$ is either equal or slightly larger than $c_{2}$, industrial production tends to be located either in country 1 or in country 2 . In particular, the probability to locate production in country 2 decreases as congestion costs in country 2 increase. On the contrary, a huge difference in production costs, for example if $c_{1}$ is ten times $c_{2}$, may lead to a spread of industrial production between the two countries, see last row of Fig. 1. This occurs if congestion costs are sufficiently high.

Cross-border spillovers also have a remarkable impact on the geographic allocation of industrial activities. If we assume that cross-border transfer of knowhow is frictionless, i.e. $\beta_{1}=\gamma_{12}$ and $\beta_{2}=\gamma_{21}$, the numerical investigation reveals that the attractiveness of country 2 decreases. This occurs if country 2 does not offer a production cost advantage, i.e. $c_{1}=c_{2}$. In fact, relocating production from country 2 to country 1 , firms avoid the costs of congestion and (due to cross-border spillovers) firms benefit from cost reduction gained by manufacturing activity in country 2. Hence, firms do not have an incentive to locate its production in country 2. In terms of policy implications, it follows that it is in the interest of the policy maker of country 1 that firms try to develop the capability to exploit inter-country flows of know-how due to external spillovers. On the contrary, the policy maker of country 2 where congestion costs matter, does not find it equally beneficial that firms can transfer know-how between countries. To increase the rate of industrial activity in its country 2, the policy maker has to aim at reducing the costs of congestion. Moreover, comparing the first row of Fig. 1, which shows the location patterns when there are no external spillovers $\left(\gamma_{12}=\gamma_{21}=0\right)$, with the first row of Fig. 3, which shows the location patterns when there are external spillovers, it also becomes apparent that external spillovers eliminate the occurrence of inefficient off-shoring of manufacturing activity that may occur when unit production costs are identical, i.e. $c_{1}=c_{2}$. Indeed, the comparison shows that the set of initial conditions that leads to location patters with inefficient off-shoring of manufacturing to country 2 (see the yellow region in Fig. 1) disappears if there are cross-border spillovers. In other words, the presence of cross-border spillovers contributes to eliminate inefficient location patterns and favor the location of manufacturing activity in country 1 if congestion costs arise only in country 2 . Hence, the policy maker of country 2 which is a suboptimal manufacturing location has an incentive to limit external spillovers. In contrast, the policy maker of country 1 which is the more efficient manufacturing location has an incentive to boost external spillovers since in this case firms move their manufacturing activity to the most efficient country without losing the cost reduction due to know-how developed in the less efficient country. 
The situation changes significantly when country 2 has an advantage in terms of unit costs, i.e. $c_{2}<c_{1}$; see the second and third row of Fig. 3 . In this case, firms that manufacture in country 2 benefit from both smaller unit costs of production and cross-border spillovers coming from country 1. Nevertheless, when congestion costs increase, the competitive advantage from producing in country 2 due to the smaller unit costs of production is diminished by an increasing congestion effect and, consequently, country 1 becomes increasingly attractive. Notwithstanding, keeping some production activity in country 2 is still beneficial. In fact, in this case the effect of the congestion costs is reduced since the concentration of production activity in country 2 is decreased. The evolutionary process of location choice leads to a situation where part of the manufacturing activity occurs in country 1 and the remaining part is carried out in the off-shore country 2. Mathematically, this is reflected by the presence of the asymptotically stable internal fixed point $x^{*} \in(0,1)$, which is marked in red in the second row of Fig. 3. The presence of asymmetric unit costs results in location patterns that are represented by a suboptimal equilibrium. Specifically, the asymptotically stable fixed point $x^{*}$ is never an optimal equilibrium as specified in Theorem 4 . Then, in case of a limited cost advantage for country 2 , the economic policy implications related to external spillovers change.

Comparing the second row of Fig. 1 and the second row of Fig. 3, we observe that for country 2 it is advantageous if external spillovers exist, while it is not beneficial for country 1 . Indeed, as long as congestion costs are small, the presence of external spillovers drives firms to off-shore the entire production activity to country 2 . In fact, the fixed point $x=0$ is the only locally asymptotically stable equilibrium as indicated by the yellow region in Fig. 3. Moreover, if congestion costs increase, country 2 loses its attractiveness but the firms still benefit from having some part of the production activity there. However, there is a trade-off between external spillovers and local unit costs of production. In fact, if country 2 has much smaller unit costs of production (excluding internal and external spillovers) than country 1 , for example $c_{1}$ is ten times $c_{2}$, then the cost reduction due to internal and external spillovers is limited in country 2 since the base unit costs are already relatively low compared to country 1 . In this situation, country 1 benefits more from external spillovers. This effect becomes obvious by comparing the last row in Fig. 3 and the last row of Fig. 1. A similar scenario is observable if the capability of firms to absorb external spillovers reduces.

In case of asymmetries between internal and external spillovers, the location patterns and the economic implications are different. We start the analysis by considering a situation where know-how developed in country 1 can be perfectly transferred to reduce costs in country 2. Conversely, know-how developed in country 2 cannot (or can only be partially) transferred to country 1 . Such asymmetric external spillovers obviously favor off-shoring manufacturing activity to country 2. Figure 4 depicts a scenario where a firm producing in country 2 benefits from external spillovers while a firm producing in country 1 does not $\left(\gamma_{12}=0\right.$ while $\left.\gamma_{21}=\beta_{1}\right)$. Comparing it with Figs. 1 and 3 , we observe that the effect of such asymmetric external spillovers is to increase the yellow region, 

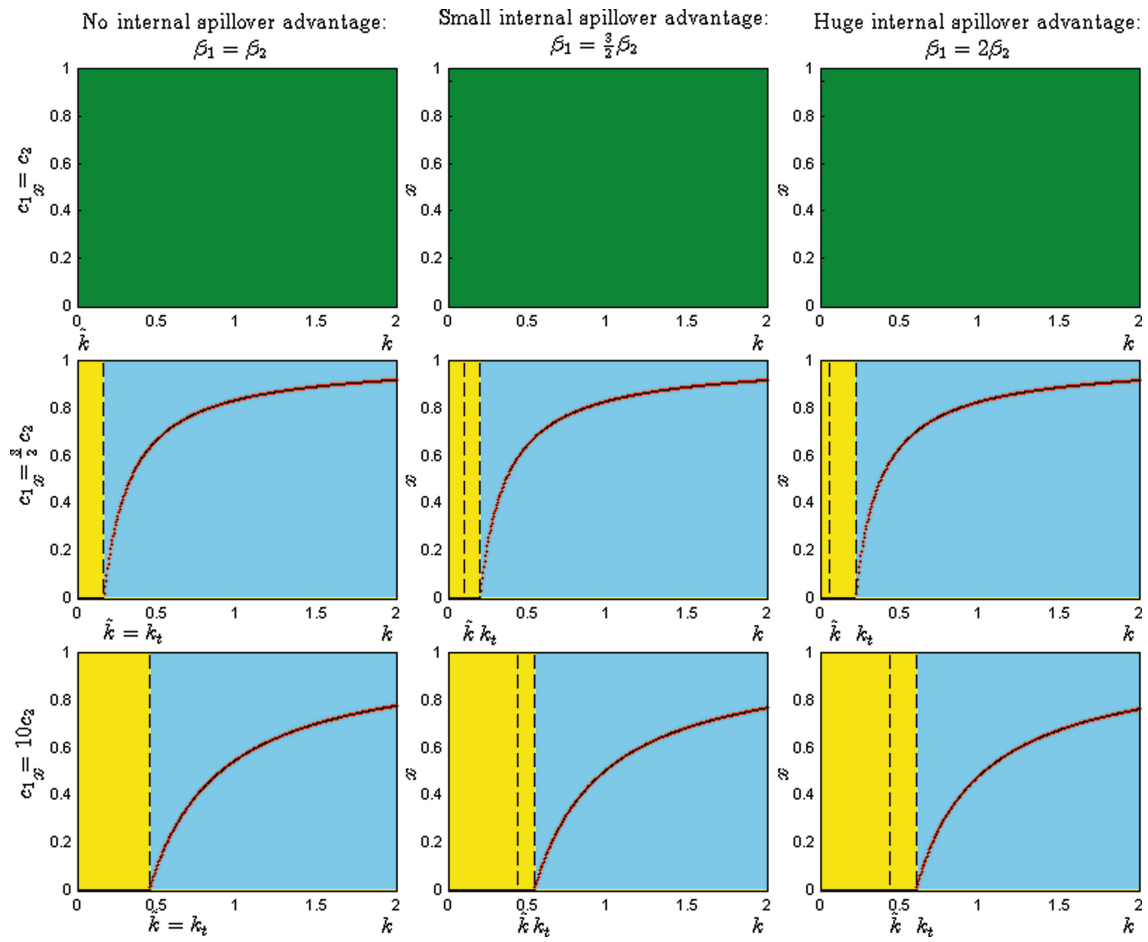

Fig. 3. Parameter setting as in Fig. 1, except $\gamma_{21}=\beta_{1}$ and $\gamma_{12}=\beta_{2}$.

i.e. the set of initial conditions that lead to long run off-shoring of production to country 2. The expansion of the yellow region occurs even when $k>\hat{k}$, i.e. when off-shoring the production to country 2 is a suboptimal location strategy as specified in Corollary 1.

Hence, it is possible to conclude that asymmetric external spillovers that favor off-shoring to country 2 cause long run suboptimal location patterns. It is also worth highlighting that the effects of these asymmetric external spillovers vanish when country 2 has a large cost advantage in comparison to country 1 . In this case, country 2's cost advantage is further increased by cost-reducing externalities coming from cross-border spillovers. In this case, the location patterns are mainly affected by the congestion costs rather than by the production costs. Comparing the bifurcation diagrams in Figs. 4 and 3, we observe that the presence of an asymmetry between internal and external spillovers in country 2 gives rise to a qualitative change of the bifurcation structure of the location patterns. Here, when congestion costs increase and the value of $k$ crosses the bifurcation value $k_{F} \approx 1$, we move from a situation in which the firm chooses to off-shore production to country 2 to a scenario in which the production is only partially off-shored to country 2 . In particular, for $k=k_{F}$, see (5), two internal fixed points appear through a fold bifurcation. One of these two equi- 

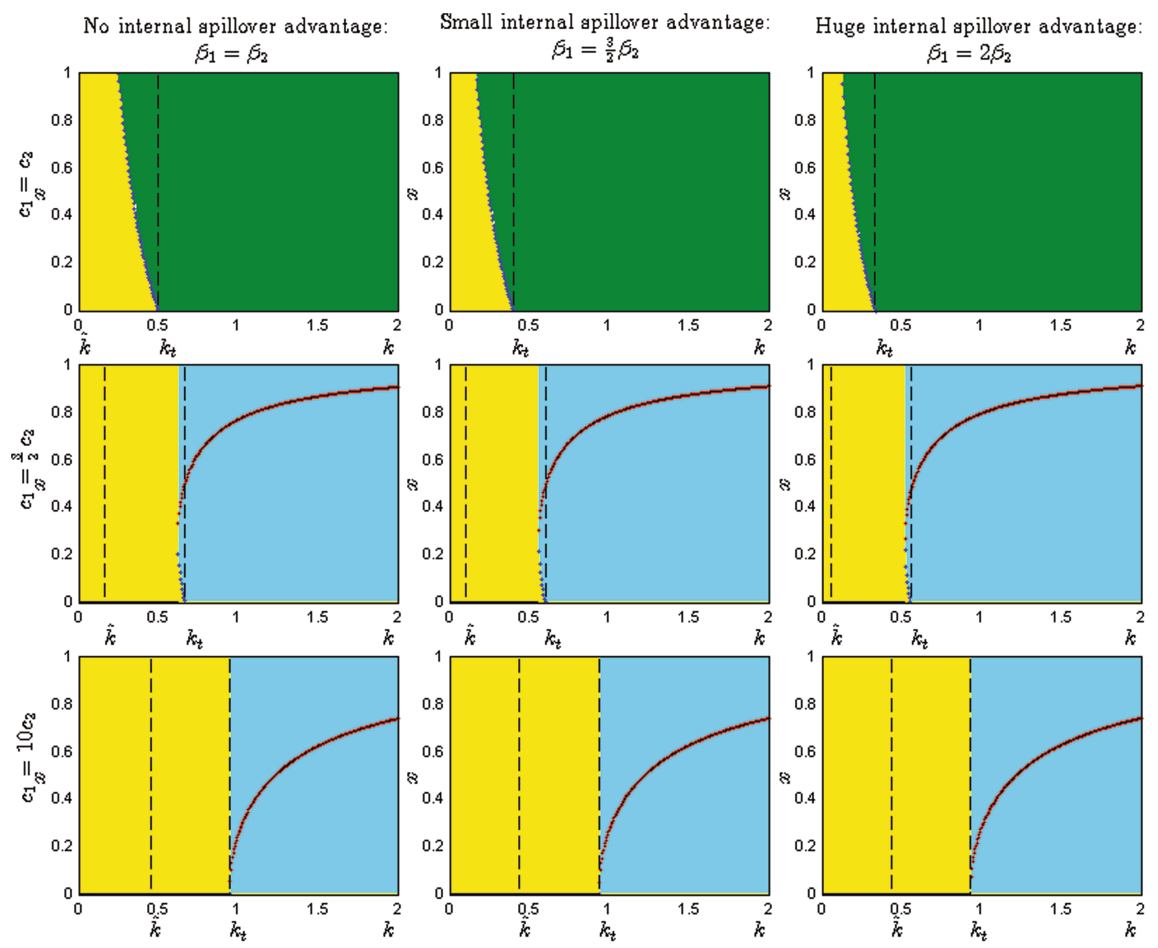

Fig. 4. Parameter setting as in Fig. 1, except $\gamma_{12}=0$ and $\gamma_{21}=\beta_{1}$.

libria is a repellor and is marked in blue, while the other one is an attractor and is marked in red. The repellor lies at the border of the basins of attraction of the fixed point $x=0$ and of the other internal fixed point $x^{*}$. In this case, production will be off-shored to country 2 only if the majority of firms have already off-shored their production activity. Otherwise, total production activity will be spread between the two countries in the long run. Although the dynamic scenario just described is interesting as it is characterized by bi-stability and, hence, path dependence, it is, however, not robust with regard to variations in congestion costs. More precisely, immediately after the value for $k$ (representing congestion costs) crosses the threshold value where the fold bifurcation occurs, it crosses another bifurcation value, namely the transcritical bifurcation value $k_{T_{1}}$. Through this bifurcation, the unstable internal fixed point merges with the fixed point $x=0$ and disappears while the fixed point $x=0$ becomes unstable. For further increasing congestion costs, total production activity is spread between the two countries and the internal equilibrium is the only asymptotically stable fixed point. Its basin of attraction is represented by the cyan region. Numerical simulations, which are not reported here, reveal that the qualitative effect of asymmetric external spillovers in favor of country 2 is the same as the one just described whatever the magnitude of the asymmetry. 
An interesting effect can be observed when know-how can be transferred from country 2 to country 1 , but cannot be transferred (or at least can only be partially transferred) from country 1 to country $2\left(\gamma_{12}=\beta_{2}\right.$ and $\left.\gamma_{21}=0\right)$. In the presence of such asymmetric external spillovers that work in favor of country 1 and whenever country 2 has a cost advantage over country 1 , the attractiveness of country 2 increases when the internal spillovers $\beta_{2}$ in country 2 decreases. This argument can be understood by observing the changes in the yellow region depicted in the second and third rows of Figs. 5 and 6 . Moving from the left column (where $\beta_{2}=\beta_{1}=1$ to the right column (where $\beta_{2}=\beta_{1} / 2=1 / 2$ ) shows that the yellow region increases when $\beta_{2}$ decreases. As a consequence, in terms of implications for economic policy, the policy maker of country 2 can decrease internal spillovers in its territory to increase the likelihood of attracting industrial production.
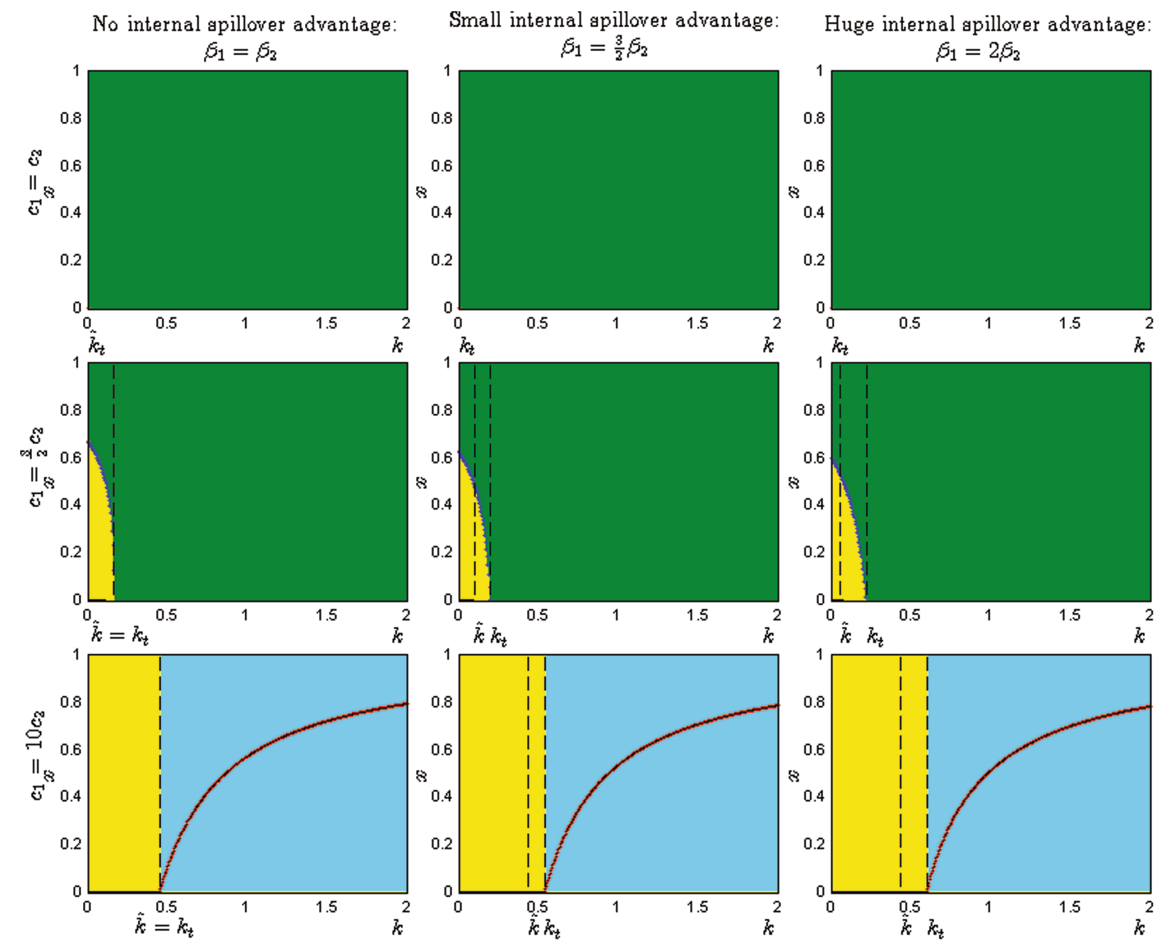

Fig. 5. Same parameter setting as in Fig. 1, except $\gamma_{12}=\beta_{2}$ and $\gamma_{21}=0$. (Asymmetric spillovers in favor of country 1 )

To conclude our analysis, we point out that our investigation revealed that whenever country 2 has an advantage in terms of unit production cost over country 1 , congestion costs make production in country 2 less profitable and reduce 

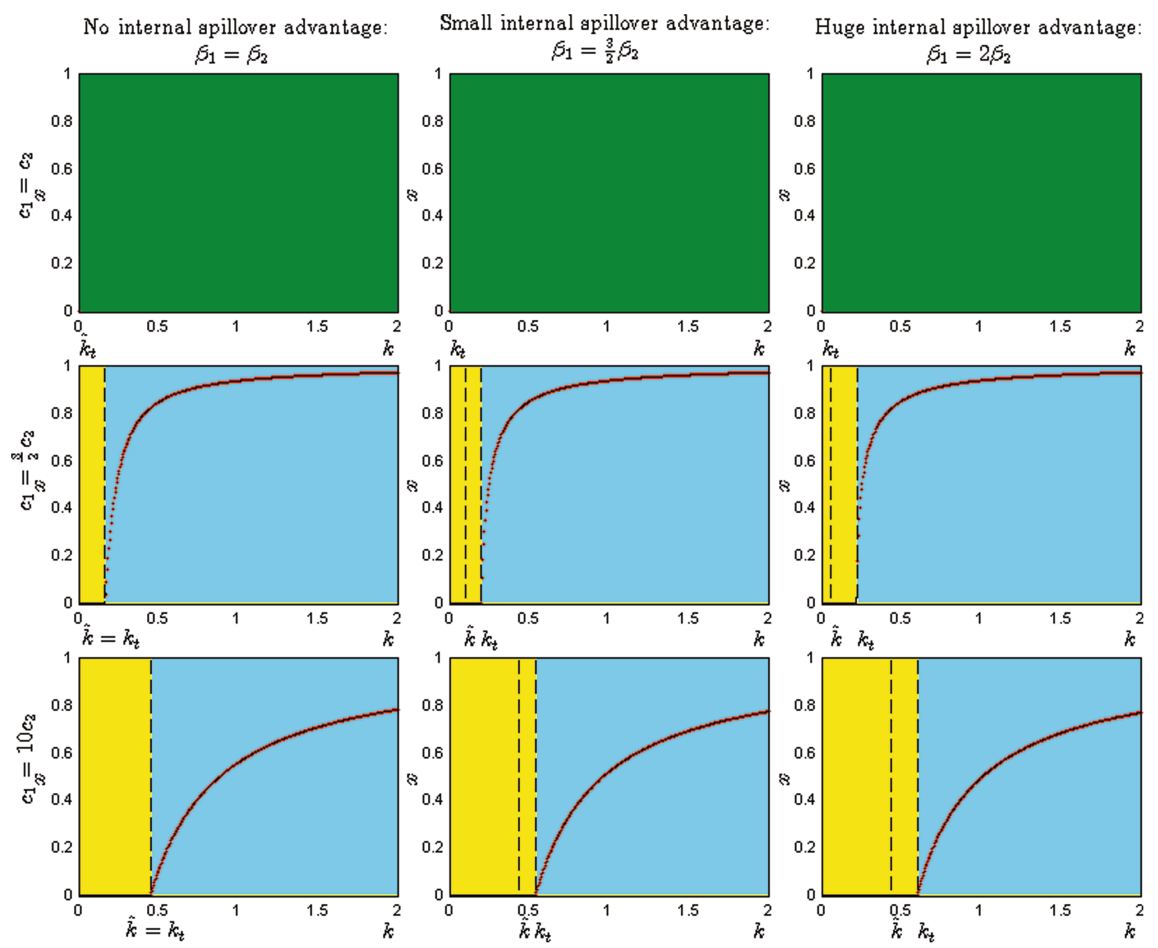

Fig. 6. Same parameter setting as in Fig. 1, except $\gamma_{12}=\beta_{2}$ and $\gamma_{21}=\frac{1}{2} \beta_{1}$. (Asymmetric spillovers in favor of country 1)

the off-shoring activities of firms. Our analysis also shows, however, that the presence of congestion costs does not eliminate off-shoring activity completely.

\section{Conclusions}

In this paper, an evolutionary mechanism for choosing the location of manufacturing is proposed. The model is employed to study the question how the long-run off-shoring and back-shoring patterns of a population of firms is affected by differences in unit production costs, within-country spillovers, cross-border spillovers, and congestion costs. The investigation reveals that a manufacturing site that offers lower unit production costs becomes more attractive and causes an off-shoring wave. This competitive advantage can be eroded by asymmetric cross-border spillovers, by positive congestion costs, or by a combination of the two. Although these factors influence off-shoring decisions, they rarely lead to total re-shoring of production activities to the home country if it suffers a rather large disadvantage in terms of unit production costs. This underlines that unit production costs are indeed a key factor which drives location choices for MNEs. A fundamental role is played by cross-border spillovers as well. These spillovers 
tend to reduce the occurrence of location patterns that lead to suboptimal equilibria and favor the geographic dispersion of manufacturing activity.

These findings are obtained by analyzing the endogenous location patterns that emerge in the long run if a population of firms choose manufacturing locations based on relative production costs. The logic of the process that governs the dynamic evolution of location choices of firms is intentionally simple: if a location currently offers a production cost advantage, then the share of firms which move production activities to this country will increase. We also took into account that there might be some inertia in this process of switching between manufacturing sites as moving production activities from one country to another is costly and takes time. What we do not take into account in our model is that MNEs are typically active in oligopolistic markets and, therefore, strategic interactions and intertemporal objectives play a crucial role. Further, MNEs are interconnected through the supply side as they share common suppliers which is a further source for strategic linkages. In this respect, our contribution differs from Alcácer and Chung (2007) and Alcacer et al. (2015), where the location choices of firms are analyzed assuming an oligopolistic industry. Papers along this promising line of research explore how rivalry and differential knowledge accumulation among competitors is affected by the multinational enterprises' geographic expansion across countries. The location choice of the firms impacts the accessibility of certain markets and firms take location decisions also to enhance and protect their relative competitive positions. The analysis focuses on how rivalry and competition influences the location decisions of multinational enterprises. In this way, these contributions integrate rivalry and location choices in multi-stage, dynamic settings. Another aspect we do not pursue in our contribution is the location of research and development activities of firms. This aspect has been investigated in the International Business literature, see, e.g., Belderbos et al. (2008). These elements, as well as the introduction of an outside option as in Bischi et al. (2003a), are key elements that can have a strong impact on the off-shoring process. The introduction of these further elements in our setup is left for future research.

\section{Disclosure Statement}

No potential conflict of interest was reported by the authors.

Acknowledgements. The authors thank the participants at the GeComplexity Conference in Crete 2016 for valuable comments and suggestions on an earlier draft of this paper. Special thanks go to J. Tuinstra (University of Amsterdam) for hosting the first meeting of the Working Group 3 of the ISCH COST Action IS1104, from which the current work started. Special thanks also go to Mario Pezzino for his valuable suggestions. Financial support was provided by COST Action "The EU in the new complex geography of economic systems: models, tools and policy evaluation" and in the framework of the research project on "Dynamic models for behavioral economics" financed by DESP-University of Urbino. 


\section{Appendix}

Proof (Proof of Theorem 1). The fixed points of model (2) solve the equation

$$
x^{*}=(1-\alpha) x^{*}+\alpha x^{*} \frac{1}{x^{*}+\left(1-x^{*}\right) e^{\beta\left(C_{1}\left(x^{*}\right)-C_{2}\left(x^{*}\right)\right)}} \Leftrightarrow\left\{\begin{array}{c}
x^{*}=0 \\
x^{*}=1 \\
C_{1}\left(x^{*}\right)=C_{2}\left(x^{*}\right)
\end{array}\right.
$$

Thus, the equilibria of the model are 0,1 and the roots, in $(0,1)$, of the following polynomial

$$
p(x)=C_{1}(x)-C_{2}(x)
$$

where $C_{1}(x)-C_{2}(x)$ are decreasing and convex functions in $[0,1]$, hence they have at most two intersections in $[0,1]$. The numerator of $p(x)$ is a third degree polynomial.

which are at most three. The eigenvalue associated to model (2) is

$$
\lambda(x)=1-\alpha+\alpha \frac{1}{x+(1-x) e^{\beta p(x)}}-\alpha x \frac{1-e^{\beta p(x)}+(1-x) \beta \frac{\partial p(x)}{\partial x} e^{\beta p(x)}}{\left(x+(1-x) e^{\beta p(x)}\right)^{2}}
$$

It follows that the eigenvalue associated to equilibrium $x=0$ and the one associated to equilibrium $x=1$ are, respectively

$$
\lambda(0)=1-\alpha+\alpha e^{\beta\left(k-k_{T_{1}}\right)} \quad \text { and } \quad \lambda(1)=1-\alpha+\alpha e^{\beta \frac{c_{1}-c_{2}+c_{1} \gamma_{21}-c_{2} \beta_{1}}{\left(1+\beta_{1}\right)\left(1+\gamma_{21}\right)}}
$$

where $k_{T_{1}}$ is given in (3). Then, since $\lambda(0), \lambda(1)>0$, imposing the classical stability conditions, we have that the fixed point $x^{*}=0$ is locally asymptotically stable when $k<k_{T_{1}}$, it undergoes a bifurcation of eigenvalue 1 at $k=k_{T_{1}}$, and it is unstable for $k>k_{T_{1}}$. Similarly, the fixed point $x^{*}=1$ is locally asymptotically stable when $\frac{c_{1}}{c_{2}}<\frac{1+\beta_{1}}{1+\gamma_{21}}$, it undergoes a bifurcation of eigenvalue 1 at $\frac{c_{1}}{c_{2}}=\frac{1+\beta_{1}}{1+\gamma_{21}}$, and it is unstable for $\frac{c_{1}}{c_{2}}>\frac{1+\beta_{1}}{1+\gamma_{21}}$. Being $[0,1]$ an invariant region for model $(2)$, when fixed points 0 and 1 are both either stable or unstable at least an internal fixed point has to exist.

For $\frac{c_{1}}{c_{2}}=\frac{1+\beta_{1}}{1+\gamma_{21}}$, one root of $p(x)$ is 1, i.e. $p(x)=(x-1) g(x), \lambda(1)=1$ and $T^{\prime \prime}(1)=\alpha \beta\left(k-k_{T_{2}}\right)$. By imposing $T^{\prime \prime}(1)>0$, we have that $x=1$ is semiasymptotically stable from the left when $k>k_{T_{2}}$. Analyzing the dynamics of the model w.r.t. the invariant region $[0,1]$, the condition $k>k_{T_{2}}$ implies the local stability of $x=1$. The remainder of the Theorem follows by classical eigenvalue analysis.

Proof (Proof of Theorem 2). For $k=0, C_{1}(0)>C_{2}(0)$, and either $\beta_{1}>\gamma_{12}$ or $\beta_{2} \neq \gamma_{21}$, the numerator of $p(x)$ becomes a polynomial of degree one since $A=B=0$. Its unique root is $x^{*}$ as given in (4), which is then the unique possible equilibrium of the model in $(0,1)$. By straightforward algebra it follows that $0<x^{*}<1$ if and only if $C_{1}(1)<C_{2}(1)$. Since $p(x)=C_{1}(x)-C_{2}(x)$ 
is a polynomial of degree one with its root $x^{*}$ in $(0,1)$ for $C_{1}(1)<C_{2}(1)$, it follows that $C_{1}(x)<C_{2}(x)$ for $x \in\left(x^{*}, 1\right]$ and $C_{1}(x)>C_{2}(x)$ for $x \in\left[0, x^{*}\right)$. From which it follows that $x^{*} \in(0,1)$ is always a repellor. Imposing the classical stability condition to eigenvalues in (12), the first part of the Theorem follows. For $k=0, C_{1}(0)=C_{2}(0)$, and either $\beta_{1}>\gamma_{12}$ or $\beta_{2} \neq \gamma_{21}$, let us note that $\forall x$ it holds $p(x)>0$ when $C_{1}(1)>C_{2}(1)$, the numerator of $p(x)=0$ when $C_{1}(1)=C_{2}(1)$ and $p(x)<0$ when $C_{1}(1)<C_{2}(1)$. Then, the second part of the Theorem follows. Let $k=0, \beta_{1}=\gamma_{12}, \beta_{2}=\gamma_{21}, \beta_{1}=\beta_{2}$. Then $p(x)=0 \forall x$ when $c_{1}=c_{2}$ and $p(x)>0$ when $c_{1}>c_{2}$. Thus the third part of the Theorem follows.

Proof (Proof of Theorem 3). For $\beta_{1}=\gamma_{21}, \beta_{2}=\gamma_{12}$ and $c_{1}=c_{2}$, we have $p(x)<0 \forall x \in(0,1)$, thus $\mathscr{B}(1)=(0,1]$. For $\beta_{1}=\gamma_{21}, \beta_{2}=\gamma_{12}$ and $c_{1}>c_{2}$, it becomes a polynomial of degree less than three. In particular, for $\beta_{1} \neq \beta_{2}, p(x)$ becomes a polynomial of degree two, the roots of which are given by:

$$
x_{1,2}^{*}=\frac{\left(1-\beta_{1}+2 \beta_{2}\right) k \pm \sqrt{\left(1-\beta_{1}+2 \beta_{2}\right)^{2} k^{2}+4 k\left(\beta_{1}-\beta_{2}\right)\left(c_{2}-c_{1}+\left(1+\beta_{2}\right) k\right)}}{2 k\left(\beta_{2}-\beta_{1}\right)}
$$

Since $0<\frac{\left(1-\beta_{1}+2 \beta_{2}\right)}{2\left(\beta_{2}-\beta_{1}\right)}<1$ if and only if $\beta_{1}>1+2 \beta_{2}$ and $\Delta=0$ if and only if $k=k_{F}$, where $k_{F}$ is given in (5), it follows that, for $\beta_{1}>1+2 \beta_{2}$, at $k=k_{F}$ two internal fixed points, i.e. $x_{1,2}^{*}$ in (13), appear through a fold bifurcation. Since $p(1)=C_{1}(1)-C_{2}(1)>0$, by continuity of $p$ it has to be $p(x)=C_{1}(x)-$ $C_{2}(x)>0$ for $x \in\left(x_{1}^{*}, 1\right), p(x)<0$ for $x \in\left(x_{2}^{*}, x_{1}^{*}\right)$ and $p(x)>0$ for $x \in\left(0, x_{2}^{*}\right)$. Moreover, since the function that defines the dynamics of the model is increasing when $p(x)<0$ and vice versa, it follows that $x_{1}^{*}$ is either stable or loses stability through a period-doubling bifurcation and $x_{2}^{*}$ is locally unstable. Moreover, we have that $x_{1}^{*}$ increases as $k$ increases but it never reaches the value 1 , while $x_{2}^{*}$ decreases as $k$ increases and it undergoes a transcritical bifurcation, it merges with equilibrium 0 , for $k=k_{T_{1}}>k_{F}$. For $k>k_{T_{1}}$, the fixed point 0 is unstable and $x_{2}^{*}$ becomes unfeasible (it exits the invariant region $[0,1]$ ).

On the contrary, for $\beta_{1}<1+2 \beta_{2}$, we have $\frac{\left(1-\beta_{1}+2 \beta_{2}\right)}{2\left(\beta_{2}-\beta_{1}\right)}<0$ and the internal fixed point can be at most one, i.e.

$$
x^{*}=\frac{\left(1-\beta_{1}+2 \beta_{2}\right) k+\sqrt{\left(1-\beta_{1}+2 \beta_{2}\right)^{2} k^{2}+4 k\left(\beta_{1}-\beta_{2}\right)\left(c_{2}-c_{1}+\left(1+\beta_{2}\right) k\right)}}{2 k\left(\beta_{2}-\beta_{1}\right)}
$$

For, $\beta_{1}=\beta_{2}$, then there is at most one internal fixed point

$$
x^{*}=1-\frac{c_{1}-c_{2}}{k\left(1+\beta_{1}\right)}
$$

which is locally asymptotically stable. It appears through transcritical bifurcation at $k=\frac{c_{1}-c_{2}}{1+\beta_{1}}$. 
Proof (Proof of Theorem 4). Since $C_{1}(1)=\frac{c_{1}}{1+\beta_{1}}$ and $C_{2}(0)=\frac{c_{2}}{1+\beta_{2}}+k$, it follows that $C_{1}(1) \lessgtr C_{2}(0)$ if and only if $k \gtrless \hat{k}$. Moreover, setting $\phi=\gamma_{12}-\beta_{1}$, by assumption $1 \phi<0$ from which $C_{1}\left(x^{*}\right)=\frac{c_{1}}{1+\beta_{1}+\phi\left(1-x^{*}\right)}=C_{2}\left(x^{*}\right)>C_{1}(1)$ whenever $x^{*} \in(0,1)$ is a general internal equilibrium. Then, being 0 and 1 two equilibria always, the statement of the Theorem follows.

\section{References}

Adams, J.D., Jaffe, A.B.: Bounding the effects of r\&d: an investigation using matched establishment-firm data. RAND J. Econ. 27(4), 700-721 (1996)

Alcácer, J., Chung, W.: Location strategies and knowledge spillovers. Manag. Sci. 53(5), 760-776 (2007)

Alcácer, J., Dezső, C.L., Zhao, M.: Firm rivalry, knowledge accumulation, and mne location choices. J. Int. Bus. Stud. 44, 504-520 (2013)

Alcacer, J., Dezso, C., Zhao, M.: Location choices under strategic interactions. Strateg. Manag. J. 36, 197-215 (2015)

Backer, K.D., Menon, C., Desnoyers-James, I., Moussiegt, L.: 'Reshoring: Myth or reality?'. OCED Science, Technology and Industry Policy Papers (27) (2016)

Belderbos, R., Lykogianni, E., Veugelers, R.: Strategic r\&d location by multinational firms: spillovers, technology sourcing and competition. J. Econ. Manag. Strategy 17(3), 759-779 (2008)

Bischi, G.-I., Dawid, H., Kopel, M.: Gaining the competitive edge using internal and external spillovers: a dynamic analysis. J. Econ. Dyn. Control 27(11), 2171-2193 (2003a)

Bischi, G.-I., Dawid, H., Kopel, M.: Spillover effects and the evolution of firm clusters. J. Econ. Behav. Organ. 50(1), 47-75 (2003b)

Bischi, G.-I., Lamantia, F.: Chaos synchronization and intermittency in a duopoly game with spillover effects. In: Puu, T., Sushko, I. (eds.) Oligopoly Dynamics: Models and Tools, pp. 195-217. Springer (2002)

Cabrales, A., Sobel, J.: On the limit points of discrete selection dynamics. J. Econ. Theor. 57(2), 407-419 (1992)

Carlton, D.W.: The location and employment choices of new firms: an econometric model with discrete and continuous endogenous variable. Rev. Econ. Stat. 65(3), 440-450 (1983)

Coughlin, C.C., Terza, J.V., Arromdee, V.: State characteristics and the location of foreign direct investment within the United States. Rev. Econ. Stat. 73(4), 675-683 (1991)

David, P.A., Rosenbloom, J.L.: Marshallian factor market externalities and the dynamics of industrial location. J. Urban Econ. 28(3), 349-370 (1990)

Flores, R., Aguilera, R.V.: Globalization and location choice: an analyses of multinational firms in 1980 and 2000. J. Int. Bus. Stud. 38(7), 1187-1210 (2007)

Furman, J.L., Porter, M.E., Stern, S.: The determinants of national innovative capacity. Res. Policy 31(6), 899-933 (2002)

Henisz, W.J.: The institutional environment for multinational investment. J. Law Econ. Organ. 16(2), 334-364 (2000)

Hofbauer, J., Sigmund, K.: Evolutionary game dynamics. Bull. (New Series) Am. Math. Soc. 40(4), 479-519 (2003)

Jaffe, A.B., Trajtenberg, M., Henderson, R.: Geographic localization of knowledge spillovers as evidence by patent citations. Q. J. Econ. 108(3), 577-598 (1993) 
Krugman, P.: Increasing returns and economic geography. J. Polit. Econ. 99(3), 483-500 (1991)

Lee, J.Y., Mansfield, E.: Intellectual property protection and US foreign direct investment. Rev. Econ. Stat. 78(2), 181-186 (1996)

Mariotti, S., Piscitello, L., Elia, S.: Spatial agglomeration of multinational enterprises: the role of information externalities and knowledge spillovers. J. Econ. Geogr. 10(4), 519-538 (2010)

Marshall, A.: Elements of Economics of Industry. Macmillan, London (1982)

Nelson, R.: National Innovation Systems: A Comparative Analysis. Oxford University Press, New York (1993)

Rosenthal, S.S., Strange, W.: Geography, industrial organization, and agglomaration. Rev. Econ. Stat. 85(2), 377-393 (2003)

Schaffer, M.E.: Are profit-maximisers the best survivors?: a Darwinian model of economic natural selection. J. Econ. Behav. Organ. 12, 29-45 (1989)

Open Access This chapter is licensed under the terms of the Creative Commons Attribution 4.0 International License (http://creativecommons.org/licenses/by/4.0/), which permits use, sharing, adaptation, distribution and reproduction in any medium or format, as long as you give appropriate credit to the original author(s) and the source, provide a link to the Creative Commons license and indicate if changes were made.

The images or other third party material in this chapter are included in the chapter's Creative Commons license, unless indicated otherwise in a credit line to the material. If material is not included in the chapter's Creative Commons license and your intended use is not permitted by statutory regulation or exceeds the permitted use, you will need to obtain permission directly from the copyright holder.

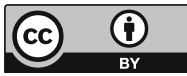

